\title{
RAZONABILIDAD POLÍTICA Y RAZÓN CULTURAL Proyección crítica de la idea de razón pública en John Rawls
}

\section{ANÍBAL FORNARI*}

\section{El problema de la diferencia en el concepto de "razón pública"}

El propósito de este artículo, en homenaje al autor recientemente fallecido, es examinar y proyectar la potencialidad diferenciada de su idea de razón pública. Entiendo esta idea en el marco de la distinción y relación activa entre, por un lado, la estructura política y su contenido moral básico común a todos los ciudadanos, en el horizonte de la justicia como equidad y de la razón como razonabilidad práctico-política, y, por otro lado, la diversidad de experiencias, fundamentaciones y convicciones religiosas, filosóficas y morales que esos mismos ciudadanos viven en el horizonte de la verdad y del bien. Es decir, en el marco del posible ejercicio cultural o pleno de la racionalidad como conciencia crítica de la experiencia humana en acto. El examen del uso público de la razón en un estado democrático constitucional es de especial importancia, pues se supone que con ello se da una respuesta política adecuada al contenido articulado de los derechos humanos fundamentales, sin los cuales la democracia sería una lamentable ficción ideológica. Entiendo aquí por ideología la construcción teórico-práctica basada en un aspecto de la experiencia social, que se preocupa por ser formalmente coherente en su desarrollo analítico, pero exaltando unilateralmente ese aspecto hasta el punto de absolutizarlo como factor explicativo, en detrimento de la especificidad de los demás factores. Por tanto, si la razón es original apertura (externa e internamente orientada) al ser de lo real manifiesto en la experiencia, considerándolo intencionalmente según la totalidad de sus factores, la mentalidad ideológica pecaría de cierta irracionalidad. Los derechos fundamentales aludidos conciernen a la

\footnotetext{
* Investigador del CONICET y Profesor de la Universidad Católica de Santa Fe (afornari@ceride.gov.ar).
} 
dimensión cultural: la libertad de conciencia, la libertad religiosa, la libertad intelectual y educativa $y$, como efectivizante de todas ellas, la libertad de asociación con sus prerrequisitos materiales. Por aquí pasa la novedad del segundo Rawls, menos preocupado por arrinconarse en la pureza formal de la idea política de justicia y más ocupado con la realidad política En efecto: "En mi Teoría de la Justicia -dice Rawls- ninguna doctrina moral de la justicia, que se diga de alcance general, se distingue de una concepción estrictamente política de la justicia. En esa obra nada se saca en limpio del contraste que existe entre doctrinas comprensivas tanto filosóficas como morales y las concepciones limitadas al dominio de lo político. En las conferencias del presente volumen [Liberalismo politico], sin embargo, estas distinciones y las ideas relacionadas con ellas son fundamentales"1.

El filósofo estadounidense evidencia la experiencia histórica que constituye su específico ethos democrático ${ }^{2}$, mantenido institucionalmente vivo por más de dos siglos. La Revolución independentista. Norteamericana (1776) no es disociable de las razones religiosas, filosóficas y educativas que la forjaron como conciencia de una continuidad histórica profunda con su tradición, incluso mediante la exigencia de reformas abolicionistas que luego desencadenan la guerra civil (1861-1865) ante la deformación de las estructuras sociales establecidas ${ }^{3}$. Tal evento de afirmación antropológica e

1 Rawls John, Political Liberalism, Columbia University Press, New York 1993; I iberalismo político, FCE, México. 1995, p. 11. De aquí en más se cita LP, traducción al español de Sergio R. Madero Báez. (Toda intercalación entre corchetes en citas es mía).

2 Cfr. Tocqueville Alexis de, Ia democracia en América, Aguilar, Madrid, 1989. Sobre la valorización católica de la libertad religiosa y de la separación entre Iglesia y estado en los Estados Unidos, ver el importante testimonio de Tocqueville expuesto en: Rawls John, The I_aw of Peoples, Harward University Press, Cambridge (Mass. EEUU) y Londres (R.U) 1999; traducción al español de Hernando Valencia Villa, El derecho de gentes y una revisión de la idea de razón pública, (en adelante DG), Paidós, Barcelona, 2001 , p. 192 , nota 6.

${ }^{3}$ La constitución de EEUU se forma con un preámbulo y siete artículos, ocho mil palabras para sancionar los procedimientos democráticos y vedar prácticamente sólo la esclavitud. La Declaración de la Independencia (4 de Julio 1776) se centra en la experiencia de la naturaleza creada de cada persona: "Juzgamos que estas verdades son por sí mismas evidentes: que todos los hombres son creados iguales; que están 
institucional de la libertad no se concibió como ruptura histórica sino ante todo como autenticación y actualización política de una tradición cultural de la libertad, que tendrá sucesivos enriquecimientos y también deformaciones. Es un ethos distinto del que posteriormente será hegemónico como rupturismo cultural del ímpetu político fundacionista de la Revolución Francesa $(1789)^{4}$, para crear, desde el voluntarismo de la mente y del poder, un mundo nuevo lanzado al progreso y liberado de toda opresión. Este costado ideológico del moderno espíritu revolucionario se efectúa como exacerbación de lo político, estatización de la sociedad y oficialización monolítica de la ideología permisible. Ésta asume la misión de re-educar a los pueblos, sumidos en patologías irrecuperables y sólo superables mediante una acción política desde la "tabula rasa" cultural, reconfigurando una unidad estatal purificada, resultado de un tipo de racionalidad sin memoria, inexperiente y ahistórica. Lo que aún hoy induce a afirmar dogmáticamente que "la religión debería estar fuera del sistema académico"s. Esta censura racionalista sobre la razón interrogativamente abierta desde lo particular a la totalidad, expresa una intolerancia que impulsa, de rebote, al fundamentalismo ${ }^{6}$. Pues expulsa el sentido religioso generador de las

dotados por el Creador de ciertos derechos inalienables, que entre estos derechos están la Vida, la Libertad y la búsqueda de la Felicidad".

${ }^{4}$ La Declaración francesa de los derechos del hombre y del ciudadano (28 Agosto 1789) se centra en el estado como fuente de los derechos del individuo: el principio de toda soberanía reside esencialmente en la Nación-estado. Ningún cuerpo o individuo puede ejercer una autoridad que no emane expresamente de ella. La Ley es la expresión de la voluntad general. El sinceramiento lógico de los totalitarismos del siglo XX está en este axioma: "nada fuera, nada sobre, nada contra el Estado" (Benito Mussolini).

${ }^{5}$ Expresión representativa de una actitud académico -despótica, contradictoria con la perspectiva cultural y política de John Rawls, hecha por Trinidad Jiménez, candidata ahora triunfante por el PSOE a la Alcaidía de Madrid, para el "Dossier Educación" de la Revista QUO, p.58, n. 84 de Septiembre 2002.

${ }^{6}$ En el Seminario interreligioso cristiano-musulmán realizado en la Universidad Gregoriana de Roma y reportado por la agencia Zenit el 21 Mayo 2003, la profesora pakistaní musulmana Anita Mir hace una caracterización conceptualmente exacta de la actitud fundamentalista. Ella "expuso su visión del fundamentalismo, al que conoce de cerca pues, como explicó, he entrevistado a muchos fundamentalistas, y en todos ellos be visto el miedo 
tradiciones culturales fuera del método asuntivo-crítico de la razón, esclarecedora de la experiencia.

La sociedad civil se resguarda en el estado como propio instrumento para su armonía básica. Ella es espacio público de libertad cultural y educativa que se recrea como lugar de iniciativa e identificación dinámica y plural. Esto es, de relaciones de amistad social, de intercambios entre las diferencias y de diálogo crítico, en instituciones libremente configuradas por sujetos culturales concretos, responsables de su propuesta pública de humanización. Si la objetivación más fundamental del reconocimiento de la libertad de conciencia (o libertad religiosa, porque la libertad es tal como decisión referida a un horizonte total y último de sentido, y no a fragmentos incoherentes de valores circunstancialmente idolatrados que inducen al fanatismo) radica en la libertad cultural, educativa y asociativa, entonces, se pone gravemente en cuestión la sustentabilidad de la democracia cuando estas objetivaciones no son constitucionalmente reconocidas y políticamente favorecidas. ¿De qué modo se manifiestan las consecuencias totalitarias de la obstrucción sistemática de las relaciones constitutivas que el yo-encarnado vive en la sociedad civil? Comento al respecto un texto de Hannah Arendt?.

a los otros, la implacabilidad, la falta de imaginación en un futuro y una nostalgia de un pasado que tal vez ni existio". La sospecha sistemática sobre el "tú" supone la eliminación del "yo" y la consecuente exacerbación desesperada del presente como abstracta y vana autoafirmación; por tanto la radical volatilización del futuro resulta de la sustitución del curso dramático y creativo de la tradición, por un somero, abstracto y arbitrario constructo ideológico-político del pasado.

${ }^{7}$ Arendt Hannah, Il pensiero secondo. Pagine scelte (a cura di Paolo Terenzi, postfazione di Luigi Amicone), BUR-Rizzoli, Milano 1999, p. 146: "El régimen totalitario sólo puede estar seguro en la media en que logra movilizar la fuerza de voluntad del hombre, para insertarlo en aquel gigantesco movimiento de la historia o de la naturaleza que usa a la humanidad como su material y no conoce ni nacimiento ni muerte. La coerción del terror total, que rige las masas de individuos aislados y las sostiene en un mundo que para ellas se ha vuelto desértico, más la fuerza autoconstringente de la deducción lógica, que prepara a cada individuo en su aislamiento contra todos los demás, se completan mutuamente para poner en marcha dicho movimiento. Tal como el terror (...) destruye todos los vínculos entre los hombres, así la autoconstricción del pensamiento ideológico destruye todos los vínculos con la realidad. La preparación llegó a su punto justo cuando los individuos 
En efecto, la conciencia se torna estrecha en su mirada, aislada y ahistórica en el sentimiento de sí misma, porque no ingresa en el diálogo crítico a través del encuentro con la presencia preferencial y concreta de maestros que despiertan la energía del preguntar y la atención de la sensibilidad. La admiración del yo encarnado por lo existente captado en la relación sensible con lo real, que despierta el preguntar de la razón por el significado a través de los nexos que refieren a la presencia inabarcable y desbordante del acto de existir, tiende a ser sustituida por la inmersión fatalista en el eterno retorno de la totalidad social y material anónima, que se recicla con la humanidad designificada. La capacidad personal de experiencia y de pensamiento se banaliza por falta de confrontación con la grandeza de una propuesta sustancial de identificación última, desafiante ante todo desde la propia tradición histórico-cultural. La educación en la verificación crítica y sistemática de esa hipótesis de sentido dentro del camino acompañado de la propia experiencia elevada a juicio y discernimiento, tiende a ser sustituida por la circularidad solitaria del solo razonamiento en su propia constricción lógico-ideológica, que diluye la capacidad de diferenciación objetiva entre lo verdadero y lo falso. La libertad de conciencia, entonces, se realiza en la libertad educativa transmisora de una propuesta cultural, donde aquella se actualiza como autoconciencia del cosmos, en cuanto no se deja "privatizar" y es vivida en el espacio público de la sociedad civil como ámbito de iniciativa e identificación según la verdad.

La libertad objetiva de conciencia es facilitada en su expresividad plural cuando es apoyada por la justicia como equidad básica del estado constitucional, respecto a los diversos sujetos culturales consistentes y razonables. Su dinámica no necesita asegurarse mediante la lucha por la

perdieron contacto con sus semejantes y con la realidad circundante; pues, junto con este contacto, los individuos pierden la capacidad de experiencia y de pensamiento. El súbdito ideal del régimen totalitario no es el nazista convencido ni el comunista convencido, sino el individuo para quien la distinción entre realidad e ilusión, entre verdadero y falso, ya no existe" (trad. de AF). Esto es rerificable en la barbarización, impulsada por una generalizada abdicación educativa (coincidente con una creciente voluntad de organización educacional y mass-mediática), manifiesta en un tiempo marcado por la violencia social letal, el terror reivindicativo y la fabricación preventiva de la guerra. 
hegemonía y el uso coercitivo del poder político. Sin libertad positiva de conciencia se pone en cuestión la posibilidad misma de un real pluralismo cultural que sustente el pluralismo político democrático y, también, se licua la pretensión de que los ciudadanos participen con sus diferencias y elijan por sí mismos. Pues se les cierra la condición jurídico-política de realización auténtica de su "mismidad". La democracia sólo formal tiende a deformarse aún más como consenso autoritario de la mayoría coyuntural y como aplastamiento de la persona bajo un hipercasuístico e invasor sistema del derecho ${ }^{8}$. Restringida la vida pública a la relación individuo-estado, sólo partidariamente sociabilizada en cuanto canalizada hacia la posesión del poder administrativo, los individuos se homologan y se enfrentan para hacer prevalecer, mediante esos canales, sus contradictorios intereses inmediatos "privados", no educados en un horizonte interpersonal global del bien. La idea de estado-educador, bajo el pretexto de que la libertad de educación obstruye la educación universal del ciudadano autónomo (reducción de la existencia pública de la persona a su relación con el estado), o atenta contra la unidad política (absorción de la sociedad en el proyecto ideológico que hegemoniza las instituciones estatales), resulta de la confusión entre la responsabilidad política por la justicia como equidad, que facilita a la sociedad las condiciones efectivas de la igualdad de oportunidades, con la estatización mental y práctica de la sociedad civil, identificando lo público con lo estatal, destruyendo el sustento mismo de la cultura política democrática. "A pesar de toda su grandeza [la esfera política] es limitada, no abarca la totalidad de la existencia del hombre y del mundo. Está limitada por las cosas que los hombres no pueden cambiar según su voluntad. Sólo si respeta sus propias fronteras, ese campo donde tenemos libertad para actuar y para

8 Es sintomática la secuela de la tradición iluminista propia de la Revolución Francesa en la elaboración actual de la Carta Magna constituyente de la Unión Europea. Por un lado, se ha elaborado un poderoso conjunto de normas (57 artículos sólo en la Parte I) pensadas para reglamentar cada aspecto de la vida de los pueblos europeos. Por otro lado, en razón de una presunta "neutralidad" (que es hegemonía estatal del agnosticismo laicista) se ha organizado una férrea negativa a incluir cualquier alusión constitucional a la dimensión religiosa en general, al Cristianismo y también al Judaísmo en particular, en la configuración histórica de hecho de la identidad cultural europea. Ambos aspectos se refuerzan en una simetría inversamente proporcional. 
cambiar podrá permanecer intacto, a la vez que conservará su integridad y mantendrá sus promesas. En términos conceptuales, podemos llamar verdad a lo que no logramos cambiar, en términos metafóricos, es el espacio en el que estamos y el cielo sobre nuestras cabezas" ". El problema, entonces, se sitúa en la formulación de una institución política democrática básica que comporte la autoconciencia del valor y del límite del estado, y la valorización objetiva de lo limitante que lo trasciende, fortaleciendo su razonabilidad operativa específica. Una proyección crítica y diferenciada de la idea de razón pública de Rawls, donde lo cultural-educativo y lo político-institucional mantienen su diferencia metodológica y su consecuente relación, se conduce desde este interrogante: "La pregunta es si el poder podría y debería controlarse no sólo mediante una constitución [...], es decir, mediante factores que surgen del campo político estricto y pertenecen a él, sino también de algo que viene de fuera, que tiene su fuente en un lugar que no es el campo político y que es tan independiente de los deseos y anhelos de la gente como lo es la voluntad del peor de los tiranos"10. El relativismo es, de hecho, funcional al tirano, mientras la educación en el ideal de verdad ${ }^{11}$ emerge del espacio de aparición de la persona y de la vida pública social, a través del discurso y de la acción, que ontológicamente precede, con la posibilidad de orientarlas críticamente, las factibilidades organizativas de la esfera pública estatal ${ }^{12}$.

9 Arendt Hannah, Verdad y' politica, en: Entre el pasado y' el futuro. Ocho ejercicios para la reflexión politica, Península, Barcelona, 1996, p. 277.

${ }^{10}$ Arendt, Verdad y política..., ed.cit., p. 253.

11 Arendt, Verdad y' politica ..., ed.cit., p. 276: “Aquí está la raíz de la denominada objetividad, esa curiosa pasión, desconocida fuera de la civilización occidental, por la integridad intelectual a cualquier precio. Sin ella jamás habría nacido ninguna ciencia".

12 Arendt Hannah, La condición bumana, Paidós, Barcelona, 1993, p. 222: "El espacio de aparición cobra existencia siempre que los hombres se agrupan por el discurso y la acción, y por tanto precede a toda formal constitución de la esfera pública y de las varias formas de gobierno, o sea, las varias maneras en las que puede organizarse la esfera pública". 


\section{Unidad política, pluralidad personal y libertad cultural}

La teoría del liberalismo político de Rawls se deslinda del proyecto radical de la Ilustración ${ }^{13}$. Éste presume haber instaurado el nuevo eón del progreso basado en la autarquía de la razón, finalmente secularizada y descontaminada de las heterologías provenientes de la alteridad de la experiencia y de las tradiciones culturales. Para Rawls eso presupone ocultar la propia posición omnicomprensiva e imponer políticamente un confesionalismo laicista, que contradice la auténtica laicidad del estado ${ }^{14}$. Por el contrario -como presupuesto fáctico y positivo de una democracia real"el liberalismo político da por existente no simplemente el pluralismo, sino la realidad de un razonable pluralismo; y más allá de eso, da por sentado que, entre las principales doctrinas comprensivas razonables, algunas son religiosas"15. Darse cuenta del carácter históricamente consolidado e irreversible de la pluralidad, no sólo de culturas y doctrinas que han generado civilización, sino también entre los individuos que participan del filum de una misma tradición, es tomar conciencia de la dignidad no sólo de la esencia del hombre sino también del siempre nuevo y dramático camino existencial personal.

La positividad de la pluralidad no es caótica, y la inconmensurabilidad entre concepciones del bien, que tantas veces acentúa Rawls, no se refiere a la ininteligibilidad e incomunicabilidad que éstas padecerían entre sí, sino a lo inconducente de cualquier solución sincretista y a lo irrazonable de cualquier superposición de concepciones en una conciencia coherente. Esto evidencia

13 DG, p. 201: "No hay, ni es necesario que haya, guerra entre la religión y la democracia. A este respecto, el liberalismo político es radicalmente diferente del liberalismo de la Ilustración, que históricamente atacó a la cristiandad tradicional". ${ }^{14}$ LP, p. 13: "Oímos a veces que se hace mención al tan conocido proyecto de la Ilustración de hallar una doctrina filosófica secular, que estuviera basada en la razón $y$, sin embargo, fuera comprensiva. Se pensaba que tal doctrina estaría en consonancia con el mundo moderno, ya que se consideraba que la autoridad religiosa y la fe de las eras cristianas no serían por más tiempo dominantes. (... Pero) en todo caso, el liberalismo político, tal como yo lo entiendo, y la justicia como imparcialidad, en tanto que parte de él, no tienen tales ambiciones".

${ }^{15} \mathrm{LP}$, Idem 
la excedencia real de lo verdadero y su trascendencia alterativa respecto a las construcciones teóricas y a las configuraciones culturales que lo abordan, así como la curiosidad con que esa trascendencia provoca hacia el encuentro y el debate intercomunicativo entre ellas, en función de un "algo más" en verdad. De ahí también la necesidad intrínseca de reconocimiento de un pluralismo razonable. "El hecho decisivo - afirma Rawls- no es el del pluralismo como tal, sino el del pluralismo razonable (...). El hecho del pluralismo razonable no es una condición desafortunada en la vida humana, como podríamos considerar al pluralismo en sí, pues éste permite doctrinas que son, no sólo irracionales, sino insensatas y agresivas. Al modelar una concepción política de la justicia de manera que pueda ganarse un consenso traslapado (overlapping consensus), no la estamos sometiendo a alguna sinrazón existente, sino adaptándola y sometiéndola al hecho del pluralismo razonable, que es en sí mismo el resultado del libre ejercicio de la razón humana libre en condiciones de libertad"16.

¿Dónde se enraíza ontológicamente la "fortuna" del pluralismo razonable? San Agustín -que podría ser definido como el primer filósofo de la autoconciencia del yo encarnado- aborda la infinitud alterativa propia del deseo-de-ser (Enquietum est cor meum - mi corazón es inquieto), que llega a manifestarse en la radical problematicidad del existente humano singular en cuanto es dado pero se auto-implica en totalidad (quaestio mibi factus sum-me volví pregunta para mí mismo). Son éstos los índices de que cada existente humano es una novedad ontológica que acontece en el mundo, en cuanto no es exhaustivamente explicable, como yo-deseo-de-ser, desde sus condiciones precedentes. Es cada vez, en cuanto tal, un nuevo inicio: "Initium] ergo ut esset, creatus est bomo, ante quem nullus fuit -para que siempre existiese un inicio, es creado el hombre, antes de quien no hubo nadie"17. No se trata del

${ }^{16}$ LP, p. 146

${ }^{17}$ San Agustín, De civitate Dei (I), BAC, Madrid, 1964, XII, 20, 4; discutiendo la reducción de los individuos humanos, en el platonismo (y no sólo), a ser reiteradas réplicas de anónimas almas eternas (o de una más compleja especie animal), Agustín dice que lo propio de Dios como amor, como plenitud originaria del gozo de existir compartido en Sí-mismo y como deseo desbordante de hacer existir, "es hacer realidades nuevas, no para sí, sino para el mundo, realidades que ni antes había hecho, ni nunca dejó de prever - facere posse res, non sibi, sed mundo novas, quas neque 
comienzo de "algo" -que por otra parte ya está en curso- sino del acontecimiento de "alguien" en medio de lo que ya está, como nuevo inicio. A través de la iniciativa del lenguaje (razón-sentido) y de la acción (libertadfelicidad), abre en el mundo una referencia nueva a la totalidad y un dramático trayecto hacia ella, investido por la infinitud, en su deseo-de-ser. Arendt lo expresa así: "La pluralidad humana, básica condición tanto de la acción cuanto del discurso, tiene el doble carácter de igualdad y distinción. Si los hombres no fueran iguales, no podrían entenderse (...). Si los hombres no fueran distintos, es decir, cada ser humano diferenciado de cualquier otro que exista, haya existido o existirá, no necesitarían el discurso y la acción para entenderse. Signos y sonidos bastarían para comunicar las necesidades inmediatas e idénticas. (...) En el hombre, la alteridad que comparte con todo lo que es, y la distinción, que comparte con todo lo vivo, se convierte en unicidad, y la pluralidad humana es la paradójica pluralidad de los seres únicos. (...) Con palabra y acto nos insertamos en el mundo humano, y esta inserción es como un segundo nacimiento, en el que confirmamos $y$ asumimos el hecho desnudo de nuestra original presencia física. En la propia naturaleza del comienzo radica que se inicie algo nuevo que no puede esperarse de cualquier cosa que haya ocurrido antes"18. El pluralismo no es, entonces, una mera concesión a la facticidad histórico-social, sino que responde a la maravillosa inagotabilidad del hecho humano singular, cuyo desarrollo requiere un contexto de convivencia que dé cabida a la pluralidad razonable.

¿Cuáles son los hechos consecuentes que exigen la traducción de esta ontología fundamental de la existencia humana en la configuración del pluralismo político razonable? Lo que cuestiona la comprensión de la unidad política como homogeneidad ideológica es, además de la estabilidad histórica de las diferentes comunidades culturales, también el continuo sucederse de las generaciones en las que se manifiesta la inestable vitalidad de la

antea fecerit, nec unquam habuerit improvisas" (Ibid. 20, 3). Pues bien, la experiencia de la dimensión ontológica del nacimiento como acontecimiento de la novedad y del inicio, racionalmente explicitada, es la raíz de la autoconciencia del hombre como persona, como yo-encamado, como unicidad que viene a la existencia desde la exclusiva preferencia del Tú creador.

${ }^{18}$ Arendt, La condición bumana, ed.cit., pp. 200-201. 
historicidad. Naciendo en una tradición familiar el individuo necesita confrontarse personalmente con ella, redescubriéndola como propuesta de una hipótesis global de sentido a verificar ${ }^{19}$. La institución política cumple su finalidad salvaguardando y facilitando este trabajo interpersonal educativo, dejando abierta la posibilidad de que el individuo claudique de esa relación, o la profundice en la experiencia de una apropiación crítica o de un nuevo encuentro más correspondiente a la razón como exigencia de totalidad y a la libertad como exigencia de felicidad. Según la concepción política de la justicia, el estado brinda un espacio público de ciudadanía bien ordenado, para que la persona y su comunidad libre de pertenencia puedan empeñarse en la búsqueda y en el cultivo de la verdad y del bien, enriqueciendo, en consecuencia, la convivencia en su conjunto. La conciencia del inescrutable destino de las diferencias personales, religiosas y culturales, suscita la auténtica curiosidad y la pregunta comprometida que atraviesan la experiencia del encuentro y del diálogo. Para ello es preciso que los jóvenes y adultos se eduquen, en la vida pública de la sociedad civil, en la identificación autoconsciente como apropiación crítico-positiva de la propuesta y trayectoria fundamental de la propia tradición problematizada. Y, por eso mismo, se tornen capaces de apertura ecuménica como valorización de todo lo positivo que le aportan los encuentros con identidades diferentes. Sólo quien no pertenece a nada grande, toma como referente existencial al estado o al mercado.

Sin embargo, ¿por qué es siempre importante que la experiencia de

${ }^{19}$ Arendt, La crisis de la educación, en Entre pasado y futuro, ed.cit., p. 205: "Precisamente por el bien de lo que hay de nuevo y revolucionario en cada niño, la educación ha de ser conservadora; tiene que preservar el elemento nuevo e introducirlo como novedad en un mundo viejo que, por muy revolucionaria que sean sus acciones, siempre es antiguo y está cerca de la ruina desde el punto de vista de la última generación". No se trata de un "conservadurismo" ideológicamente imputable, sino de la autoconciencia del yo-nuevo de ser heredero creativo de una historia a innovar para bien, sin dejarse arrastrar por la obtusidad de la "tabula rasa" nihilista, que rechaza la herencia que tiene y, como consecuencia, no hace la revolución que pretende. Al respecto Cfr. Galetto, Gerardo, Educación y' política: la mediación antropológica entre la esfera pública y la esfera privada en $H$. Arendt, tesis de licenciatura en filosofía dirigida por A. Fornari, Universidad Católica de Santa Fe, 2000. 
pluralidad y diferencia cultural se articule con un ideal delimitado y razonable de unidad política? Si, por un lado, nacer significa quedar políticamente registrado por un estado y estar culturalmente lanzado a relaciones con el mundo desde una lengua materna, por otro lado, para que ese nacimiento se desarrolle sin quedar sumergido en lo colectivo precisa de la libre posibilidad de encuentros significativos (referidos a la totalidad de la existencia personal) para que la propia pertenencia a una identidad cultural no quede cautiva de la unidad política. El liberalismo político no considera en forma inmediata a la sociedad política como una comunidad ${ }^{20}$. Esto no significa carecer de objetivos morales comunes, principios y virtudes propios de la justicia política, ni tampoco rechazar los valores de las comunidades sino que, por el contrario, es esencial que estos valores se realicen y así también alimenten el "consenso por solapamiento" (overlapping consensus). "Todos los que se adhieren a la concepción política empiezan a elaborar su consenso a partir de su propio punto de vista comprensivo, y se valen de elementos de los fundamentos religiosos, filosóficos y morales que les da ese punto de vista. El hecho de que la gente se adhiera a la misma concepción política basada en esos principios no convierte su adhesión en algo menos religioso, menos filosófico o menos moral, según el caso, puesto que los fundamentos sinceramente profesados determinan la naturaleza de su afirmación"21.

La libre radicación en la propia identidad y comunidad, es incoativamente resistente a toda forma de totalitarismo político. La conciencia de ser mucho más que ciudadano de un estado significa ser irreductible a la dialéctica del todo (unidad política) y las partes (individuos sin propia referencia a la totalidad del sentido y sin pertenencia cultural comunitaria), al modo de un atomismo de elementos en un monismo colectivo. El conjunto político es pensable como sociedad abierta en la medida en que es una totalidad de totalidades. En tal sentido "considerar un desastre el pluralismo razonable es considerar también que es un desastre el ejercicio de la razón en condiciones de libertad"'22. La pluralidad de personas y sus comunidades culturales llega a configurar una unidad política en la medida en que converge en el consenso traslapado que expresa la extensión

\footnotetext{
${ }^{20}$ LP, p. 148 , nota 13.

${ }^{21}$ LP, p. 149.

22 LP, p. 18.
} 
de la identidad personal y cultural a la cultura política básica de la sociedad, que se objetiva en el consenso constitucional del estado democrático. Al respecto el liberalismo político debe resolver un doble problema. Por un lado, debe abstraerse metódicamente de toda concepción del bien a partir de este axioma: "ninguna doctrina comprensiva es apropiada, como concepción política, para un régimen constitucional" 23 . Así establece las condiciones básicas de una sociedad equitativa, duradera y estable de ciudadanos libres e iguales, diferenciados por doctrinas razonables de tipo religioso, filosófico y ético. Lo que se trata de resolver "es un problema de justicia política; no un problema acerca del más alto bien" 24 . Por otro lado, para que el pluralismo exista, para que no sea un mero modus vivendi que se agota en sí mismo diluyéndose en una sociedad de individuos homologados (en un totalitarismo edulcorado), apenas diferenciados por pareceres caprichosos y demandas irrazonables, la misma estructura política básica de la sociedad debe proveer el camino inverso que facilite la vigencia activa y libre de la dimensión cultural de los derechos humanos fundamentales antes nombrados. Para esto, el estado tampoco debe artificializarse hasta el punto de convertirse en una estructura institucional defensiva frente a la sociedad, cerrado en una imparcialidad celosa de sí misma y neutralizante de la historicidad cultural y de las idiosincracias creativas de la sociedad. Pero, para que no se estatice la iniciativa cultural de la sociedad ni haya oficialización monopólica de un sujeto cultural, Rawls señala una "primera etapa" metodológica insoslayable que establece el campo de la razón pública [política]: "en una democracia constitucional, la concepción pública de la justicia debiera presentarse, hasta donde esto es posible, como independiente de las doctrinas comprensivas religiosas, filosóficas y morales. Esto significa que la justicia como imparcialidad debe entenderse, en la primera etapa de su exposición, como un punto de vista libre que suministra una concepción política de la justicia. No suministra una doctrina específica, metafísica o epistemológica, más allá de lo que esté implicado en la concepción política misma. [...Pues] la concepción política es un módulo, una parte constituyente esencial, que de diversas maneras puede caber en varias doctrinas comprensivas razonables de las que puede obtener su apoyo, doctrinas que son durables en la sociedad regulada

\footnotetext{
23 LP, p. 138.

${ }^{24}$ LP, p. 19.
} 
por dicha concepción política"25.

\section{La "razón pública" en la tensión entre lo racional y lo razonable}

La segunda etapa de la justicia como equidad estriba en relacionar esta estructura política básica de la necesidad para todo individuo de estar incluido en un estado, con el desafío a la razón personal de adherir mediante la libertad a una forma histórica consistente y correspondiente a la verdad del ideal acerca del bien y de la felicidad (tensión trascendental constitutiva del individuo racional y libre) en una perspectiva comprensiva, que configura el propio vínculo de pertenencia y personalización. En Rawls ese horizonte de la necesidad se manifiesta doblemente: la relación política en un régimen constitucional tiene estas dos características especiales. "Primera: se trata de una relación de personas dentro de la estructura básica de la sociedad, estructura de instituciones básicas en la que entramos sólo por nacimiento y de la que salimos sólo al morir (...) La sociedad política es cerrada: llegamos a ser, a existir, dentro de ella y, por cierto, no podemos entrar ni salir de ella voluntariamente [pues saliendo de una siempre 'caemos' en otra]. Segunda: el poder político es siempre coercitivo, respaldado por la utilización de sanciones por parte del gobierno, pues sólo el gobierno posee la autoridad para utilizar la fuerza en defensa de las leyes" 26 . ¿Cuál es la consecuencia de esto en la existencia personal y comunitaria pre- y meta-estatal? ${ }^{27}$.

${ }^{25}$ LP, p. 146, las cursivas son mías.

${ }^{26}$ LP, p. 139.

${ }^{27}$ DG, o.c., p. 178 , nota 5. Aquí Rawls afirma que "el liberalismo político concuerda con David Hollembach, S.J., cuando escribe [en "Contexts of the Political Role of Religion: Civil Society and Culture", San Diego Law Review, n' 30, 1993, p. 891]: 'Entre las transformaciones aportadas por santo Tomás de Aquino no es la menos importante su insistencia en que la vida política de un pueblo no constituye la más alta realización del bien al cual dicho pueblo pueda aspirar. Esta intuición se encuentra en el onigen de las teorías constitucionales del gobierno limitado'. Efectivamente, el liberalismo político es articulable con la concepción cristiana, que distingue y jerarquiza instancias de pertenencia en el horizonte de totalidad de la realización personal: "dad al estado lo que es del estado y al Creador lo que es del 
La gente es reclamada a existir según un doble horizonte de sociabilidad: de lo razonable, por donde se implica prácticamente como ciudadano cooperante entre ciudadanos en relación al estado, desde el punto de vista de la concepción política de la justicia como equidad; y de lo racional (no restringido aquí al cálculo de un beneficio parcial -como en parte lo entiende Rawls ${ }^{28}$, operado por agentes racionales carentes de esa "forma particular de sensibilidad moral que subyace en el deseo de comprometerse en la cooperación justa..." 29 ), en cuanto los agentes "no se limitan al razonamiento medio-fin, pues quizá tomen en cuenta el equilibrio de los fines últimos según el significado que tenga su plan de vida, en conjunto, $y$ cómo encajan estos fines unos con otros y cuán bien se complementan" 30 . Lo racional ha de ser entendido, también, como un poder intelectual y moral de las personas, que las capacita en "formar, revisar y aspirar a una concepción del bien, y en la capacidad de deliberar de acuerdo con esta concepción" 31 . Entonces, si el individuo es capaz de realizar su adhesión a

Creador". Rawls concentra el surgimiento de la concepción liberal del estado limitado, sin competencias ni sobredeterminaciones en lo que respecta a las concepciones omnienglobantes, en el moderno sentido ético-político de la tolerancia y en el espíritu de la Reforma protestante, aunque no de los Reformadores mismos. La importancia del estado y el valor de lo político también implican que el bien de las personas, en este mundo, precede y excede las posibilidades y competencias del estado.

${ }^{28}$ LP, p. 67-68: "Qué es lo que distingue a lo razonable de lo racional? En el habla cotidiana, advertimos al menos una diferencia, de la que podemos dar algunos ejemplos. Decimos: 'Su proposición fue perfectamente racional, dada su fuerte posición negociadora, a pesar de lo cual fue sumamente irrazonable, e incluso excesiva' (...) Pues lo racional es una idea distinta de lo razonable y se aplica a un solo agente unificado (ya sea una persona individual o corporativa) poseedor de capacidades de juicio y deliberación, que persigue fines e intereses sólo en su propio beneficio. Lo racional se aplica a cómo se adoptan y afirman estos fines e intereses, así como a la manera de darles prioridad".

${ }^{29}$ LP, p. 69.

${ }^{30}$ LP, pp. 68-69.

${ }^{31}$ LP, p. 87. No pretendo consolidar el concepto empirista de racionalidad en Rawls, deudor de una concepción instrumental de la razón y de un sentido psicologista del bien, sino abrirlo a una dialéctica consistente entre la razonabilidad política, sobre la 
una concepción totalizante del bien, sin descuidar el punto de vista prácticopolítico de una doctrina razonable que proteja para todos la búsqueda, el hallazgo y la práctica de la relación con el bien, es porque su razón es también intencionalmente capaz de captar de modo crítico e integral, desde una perspectiva dada por su propia historicidad, un sentido del bien que potencialmente beneficie a todos. Se puede pensar no sólo el carácter correctivo de lo razonable sobre lo racional, sino también la complementariedad crítica entre ambos términos.

En efecto, que los ciudadanos desarrollen una sensibilidad por la que consideran su adhesión a los valores políticos como los más altos desde un punto de vista práctico, para participar de una convivencia bien ordenada y pluralista según valores constitucionales, significa que pretenden también desarrollar libremente la propia y libre adhesión cultural al dominio más vasto de los valores totalizantes de la existencia personal y comunitaria, que generan una auténtica sensibilidad por los valores políticos. La diferencia misma entre lo razonable y lo racional no equivale a público y privado, sino que se despliega en el espacio público de la sociedad civil donde las personas establecen múltiples relaciones y tienden, por estar dotadas de razón y conciencia moral, a configurar su autenticidad ante los otros, articulando sus convicciones últimas con su participación política. El liberalismo político intenta dar una explicación de los valores específicos del dominio político, "como un punto de vista no impuesto [es decir, alcanzado por propia convicción]. Se deja al criterio de los ciudadanos individualmente -como parte de la libertad de conciencia- resolver cómo se relacionan, en opinión de cada cual, los valores del dominio político con otros valores de su doctrina comprensiva. Porque siempre suponemos que los ciudadanos tienen dos puntos de vista: uno comprensivo, doctrinario, y otro politico; y que su punto de vista general puede dividirse en dos partes, apropiadamente relacionadas una con la otrd"32.

Rawls sugiere la necesidad de reconocer la exigencia racional de unidad y dignidad de la conciencia personal, en cuanto ejercida en el espacio

que él insiste con vigor kantiano, y la racionalidad "cultural" que él presupone y subsume casi totalmente en la primera, pero considerándola formada por concepciones omninglobantes del bien.

32 LP, p. 142 (cursivas mías, para subrayar el anclaje de mi proyección dialéctica de la razón pública). 
social de aparición y expresión pública de la persona, a través de la tensión entre dos dinámicas relacionadas e inconfundibles, que yo denomino razón pública cultural y razón pública política. El liberalismo político decae allí donde prevalece la indiferencia y el escepticismo respecto a la búsqueda de una identidad personal exigente, socialmente incidente y meta-estatal, de modo que "sería desastroso para la idea de una concepción política de la justicia verla como indiferente, o escéptica, hacia la verdad, mucho más que en conflicto con ella. Tal escepticismo o tal indiferencia pondría a la filosofía política en oposición con numerosas doctrinas comprensivas, y así haría fracasar desde el principio los objetivos de lograr un consenso traslapado" 33 . $\mathrm{El}$ "liberalismo político no (...) pone en entredicho la posible veracidad de profesiones de fe. Sobre todo, no argumenta que debiéramos ser vacilantes o inseguros, mucho menos escépticos, acerca de nuestras propias creencias. $\mathrm{Al}$ contrario: hemos de reconocer - declara Rawls- la imposibilidad práctica de llegar a un acuerdo politico razonable y viable en el juicio acerca de la veracidad de las doctrinas generales, especialmente a un acuerdo que pudiera servir para propósitos politicos... El alcance limitado de esta conclusión tiene especial importancia. Un régimen constitucional no necesita de un acuerdo acerca de una doctrina comprensiva: la base de su unidad social radica en otros elementos" 34 . Sin embargo, la distinción entre doctrinas comprensivas y concepción política de la justicia es, al par, relación activa a través del consenso traslapado, por el que "la aceptación de la concepción política no es un compromiso entre quienes sostienen diferentes puntos de vista, sino que se fundamenta en la totalidad de razones especificadas dentro de la doctrina comprensiva que profesa cada ciudadano"35.

Pueden proyectarse, entonces, sentidos diferenciados y articulados del concepto de "razón pública" según una doble dinámica: la primera (cultural y radicada en la sociedad civil) se realiza en el vasto horizonte ideal de la verdad y del bien, donde se educa en la autoconciencia de la existencia y de la pertenencia histórico-cultural. La segunda (política y radicada en el estado) se establece en el delimitado horizonte de la justicia como equidad, donde se

${ }^{33}$ LP, p. 151.

${ }^{34}$ LP, p. 79 (cursivas mías para remarcar la restricción política del concepto de "razón pública").

${ }^{35}$ LP, p. 169. 
cumple la condición de ciudadano ${ }^{36}$. La convivencia cultural pluralista es protegida y facilitada por un "ejercicio del poder político [que] es plenamente apropiado sólo cuando lo ejercemos en concordancia con una constitución, cuyos principios esenciales todos los ciudadanos libres e iguales pueden razonablemente suscribir, a la luz de principios e ideales aceptables para su razón humana común. Este es el principio liberal de la legitimidad (...). Sólo una concepción política de la justicia que todos los ciudadanos puedan razonablemente suscribir puede servir de fundamento de la razón pública [política] y de su justificación" ${ }^{37}$. La dinámica dual, asimétrica y dialéctica entre pertenencia cultural y pertenencia política es esencial para una democracia viva y se realiza idealmente en la complementariedad de esos dos matices diversos de la razón. La concepción monista de la razón pública tiende a atribuirle al estado una gama cada vez más amplia de competencias regulativas coercibles sobre las expresiones éticamente más comprometidas de la existencia interpersonal. Además, tiende a supervisar con mezquindad los valores procedentes de la sociedad y a construir muros entre estado y sociedad, bajo pretexto de que esos valores no vuelvan a invadir la esfera política. La concepción dialéctica de la razón pública, en cambio, tiende a valorizar la delimitación del espacio de juridicidad y de legitimidad

${ }^{36}$ La teoría política de Rawls podría, a mi juicio, dar lugar a un desarrollo más positivo de la idea de equidad, sin neutralizarla en una concepción a-histórica de la imparcialidad. El estado reestablece la igualdad de oportunidades y protege el espacio público de expresión y participación con el criterio de la justicia como equidad. Pero el dinamismo de esto pasa por la justicia para con la iniciativa de la sociedad, mediante el criterio subsidiariedad. Éste atribuye a la subjetividad plural de la sociedad, y no al estado, ser sujeto protagónico del desarrollo del bien común. Esta tesis fundamental surge de las 'dos ciudades' manifiestas en la filosofía de la historia de Agustín, en De civitate Dei. Cada hombre es ciudadano de 'dos ciudades' asimétricas, siendo la más abierta y totalizante aquella a la que se adhiere, desde la total libertad, en un camino operativo personal y comunitario, a la verdad en orden a la felicidad (goce del bien, frui); siendo la limitadamente totalizante aquella que se constituye como razonabilización jurídica del poder (útil porque facilita reconocer y vivir el bien, $u$ ti) mediante leyes en lo posible adecuadas pero imperfectas, para favorecer la concordia ciudadana. Dos ciudades correlativas e irreductibles en la historia: suprimiendo una la otra decae en el monismo político como libido dominandi. ${ }^{37}$ LP, p. 140. 
argumentativa de la razón pública en función estatal, sin que ello implique censurar las formas de vida de las comunidades histórico-culturales. Más aún, incita a la profundización crítica y operativa, personal y comunitaria, de la propia identidad omnicomprensiva en el espacio público de las diferencias e intercambios en la sociedad civil. A la misma esfera política del estado democrático le debería interesar nutrirse de la vitalidad axiológica de los sujetos culturales e incitar a desarrollar el criterio de razonabilidad política, ya que, para Rawls, una "concepción política razonable y eficaz puede atraerse a las doctrinas comprensivas, modelándolas, en caso necesario, para que de no razonables se vuelvan razonables" 38 .

\section{Dialéctica de la razón pública diferenciada}

La razón es pública por definición, en el sentido de que no existe algo así como una "razón privada" ${ }^{39}$. La razón pública política es una especificación ideal y práctica en función de la participación colaborativa y argumentativo-comunicativa de los ciudadanos que, desde diversas posiciones culturales referidas a una concepción política, deliberan para tomar decisiones acerca de elementos constitucionales esenciales y en asuntos de justicia básica ${ }^{40}$. Pues "es a través de lo razonable como entramos como iguales al mundo público de los demás y que nos alistamos para proponer y aceptar, según sea el caso, los términos justos de la cooperación con ellos. Estos términos, establecidos como principios, especifican las

${ }^{38}$ LP, p. 233.

39 LP, p. 210, nota 7: "La distinción entre pública y no-pública no equivale a la distinción entre pública y privada. Este asunto lo paso por alto: para mí no existe tal cosa como 'razón privada'. Existe la razón social -las muchas razones de asociaciones en la sociedad que forman el entorno cultural-; también existe, podríamos decir, la razón doméstica (...). Como ciudadanos, participamos de todas estas clases de razones...”. Entiendo, entonces, por razón pública social la que engloba, desde las diferencias culturales, a todas esas clases de razones.

${ }^{40}$ LP, p. 230: "Lo que exige la razón pública es que los ciudadanos puedan explicar su voto unos a otros en términos de un razonable equilibrio de los valores políticos públicos, y que todo el mundo entienda, por supuesto, que la pluralidad de las doctrinas comprensivas que profesan los ciudadanos sea considerada por ellos mismos un apoyo más, a menudo trascendente, para esos valores". 
razones que hemos de compartir y reconocer públicamente ante unos y otros, como base de nuestras relaciones sociales" 41 . Sin embargo, "la razón pública [política] no nos pide aceptar los mismos principios de justicia, sino que conduzcamos nuestras discusiones sobre lo fundamental en términos de lo que consideremos una concepción política. Deberíamos pensar sinceramente que nuestro punto de vista sobre la materia que tratemos está basado en valores políticos que todos puedan compartir razonablemente" 42 , actualizando la complementariedad de las dos dinámicas dentro de la idea fundamental de cooperación justa. Lo racional y lo razonable se conectan cada uno con un propio poder moral de la persona: con la capacidad (razonable) de tener un sentido de la justicia para compartir la unidad política y con la capacidad (racional) de participar de una concepción omnienglobante del bien que, en cuanto consistente, se perfila desde la reapropiación actual de una tradición cultural e intelectual. "Como ideas complementarias, ni lo razonable ni lo racional puede existir lo uno sin lo otro"43.

Revisada la idea que Rawls tiene de la razón, la apuntada distinción tiene cierta convergencia con la afirmación clásica de la relativa autonomía de la filosofía práctica y política, respecto a la filosofía especulativa ${ }^{44}$. Incluso

${ }^{41}$ LP, p. 71.

42 LP, p. 228.

${ }^{43}$ LP, p. 70.

44 "Una de las distinciones más profundas entre las concepciones de la justicia se hace entre las que permiten una pluralidad de doctrinas comprensivas razonables, aunque opuestas entre sí y cada una con su propia concepción del bien, y aquellas que sostienen que no existe sino una concepción válida del bien, que tienen que reconocer todos los ciudadanos plenamente razonables y racionales", LP, p. 138. Aquí Rawls asigna a Platón, Aristóteles y Tomás de Aquino, la identificación total entre lo racional y lo razonable, de modo que las instituciones políticas sólo son justificables si promueven efectivamente ese bien, pues no existe sino una concepción del bien razonable y racional. Pero quien estudia la tradición filosófica platónico-aristotélico-tomasiana advierte, por un lado, que la afirmación necesaria del carácter único del último bien no significa que la razón por sí misma lo logre concebir de la misma manera, porque su realidad la trasciende y, sin la revelación histórica, la razón se desvía por oscuros equívocos especulativos; por otro lado, que 
porque en la búsqueda e identificación del bien último de la existencia, a través de la realidad como signo, la razón involucra al hombre entero y no puede disociarse de la libertad. Por eso, "las personas razonables considerarán irrazonable utilizar el poder político, en caso de que lo tengan, para reprimir puntos de vista comprensivos que no son [políticamente] irrazonables, aunque difieran de su propio punto de vista. Esto es así porque, dado el hecho del pluralismo razonable, un fundamento público y compartido de justificación [política de una única concepción del bien] que se aplique a las doctrinas comprensivas no existe en la cultura pública de una sociedad democrática"45. Las personas y comunidades que viven una efectiva y crítica pertenencia ideal que juzga la vida política desde su posición metapolítica, no necesitan hacer uso del poder del estado (signo de debilidad racional que se vale del uso de la fuerza) para garantizar su vigencia. Ellas se dirigen a la razón y a la libertad de los individuos como propuestas de sentido y formas de vida públicamente testimoniables en la sociedad civil. Este tipo de identidades participan desde sus propios criterios en la concepción política de la justicia como equidad, expresándola en la laicidad del estado. De este modo, el estatismo educativo representa una forma institucionalizada de inculcación ideológica y de confesionalismo coactivo (laicista, irreligioso o religioso), que conculca los resortes objetivos del ejercicio pleno de la razón y de la libertad de conciencia, reduciéndolos a la privacidad. Se reprime así la doble dinámica de la razón pública que propongo, desvitalizando la libertad cultural de la sociedad civil y obstruyendo políticamente la posibilidad de conversión de las personas desde una identidad a otra que corresponda mejor a las exigencias constitutivas del yo, sin que ello implique sanción política alguna, directa o indirecta.

El laicismo, forjado por el racionalismo, presume ser la doctrina secular neutral y que representa naturalmente a la razón pública. Así pretende la hegemonía política en las instituciones educativas y científicas estatales como si ella fuese la portadora sin más de la validez argumentativa universal y de la cultura pública común. Pero esta pretensión indica una carencia de

la razón práctica tiene el ámbito de oscilación propio de lo razonable, que no está en total continuidad deductiva con la razón especulativa.

${ }^{45}$ LP, p. 77. 
autoconciencia crítica. Para Rawls es una falacia hablar de razón secular entendiendo por ello que "mientras no deberían invocarse razones religiosas y doctrinas sectarias para justificar las leyes en una sociedad democrática, los argumentos seculares sí son válidos. Pero ¿qué es un argumento secular? Algunos dicen que es un argumento reflexivo y crítico, públicamente inteligible y racional (....) Por supuesto, algunos de esos argumentos pueden ser reflexivos, racionales y por tanto seculares. Sin embargo, una característica central del liberalismo es que considera a esos argumentos de la misma forma que los argumentos religiosos y, en consecuencia, estas doctrinas seculares no suministran razones públicas" ${ }^{46}$. Los argumentos reflexivos, racionales, críticos, públicamente inteligibles y por tanto seculares, también pueden ser parte de diversas concepciones globales, religiosas o irreligiosas. Incluso muchas de éstas pueden ser políticamente razonables e inducir a los ciudadanos que adhieren a ellas a "considerar las razones que razonablemente pueden intercambiar [criterio de reciprocidad y simetría política entre identidades culturales consistentes] cuando están en juego cuestiones políticas fundamentales" 47 . Otras concepciones globales, religiosas e irreligiosas, no son políticamente razonables pero pueden llegar a serlo si, como fue dicho, también hay una incidencia de la misma concepción política razonable, en cuanto a "atraer y modelar" esas doctrinas comprensivas, a través de la experiencia histórico-social de la libertad.

Por su misma lógica posesiva, el poder tiende a cerrarse sobre sí mismo-para esto es insuficiente la necesaria tipartición republicana del poder-, y quien hegemoniza la representación política y gobierna el estado tiende a erradicar el pluralismo o a reducirlo a la sola multiplicidad del ciudadano individual, sin considerar las libres comunidades culturales a las que ellos adhieren para favorecer la autoconciencia de su existencia. Por eso, para Rawls -como mínimo- "es esencial que la idea de razón pública [política] no critique ni ataque a ninguna doctrina global, religiosa o no religiosa, salvo si tal doctrina es incompatible con los fundamentos de la razón pública y de la sociedad democrática" 48. Más bien hay que favorecer a la persona para que incorpore la propia "doctrina global, religiosa o no-religiosa, al debate político en cualquier momento, a condición de que, a su debido tiempo, ofrezca las

\footnotetext{
46 DG, pp. 171-172.

${ }^{47}$ DG, p. 155.

${ }^{48}$ DG, p. 156.
} 
razones públicas que sustentan los principios y las políticas que la doctrina global dice preferir" 49. Este es el requisito de la "estipulación" 50 por el que el razonamiento público acerca de una toma de posición tiende a la "justificación pública, que no es simplemente el razonamiento válido sino la argumentación dirigida a otros; parte de premisas que aceptamos y que pensamos que los otros razonablemente podrían aceptar, y llega a conclusiones que pensamos que ellos también razonablemente podrían aceptar" 51 . En tal sentido, en orden a la comunicabilidad transcultural y a la expresión política de la propia autoconciencia, es preciso que toda concepción englobante (religiosa o irreligiosa) esté atravesada por la "laicidad" no racionalista de la razón filosófica (la denominada "razón argumentativa secular"). La apertura a sí-mismo y al otro desde la activación de las estructuras fundamentales comunes de toda experiencia y razón humanas, es necesaria tanto para el aspecto político cuanto para el aspecto cultural de la "razón pública" y para el desarrollo dialógico de la autoconciencia.

Este tener en cuenta al otro en la búsqueda de un plano común de justificación de lo que ha de adquirir un valor normativo para todos, supone el pluralismo cultural. Sin embargo, la razón última del pluralismo no es el mero multiculturalismo. El criterio profundo de la convivencia humana es la afirmación del hombre en cuanto tal, es decir, la afirmación de su realidad, la afirmación del otro, simplemente porque existe 52 . De modo que el ideal concreto inmanente a la sociedad es el encuentro de libertades comprometidas con su vida y por ende con su identidad última. El contrato constitucional que regula la vida en común debe entonces favorecer esa dinámica libre de identificación y de encuentro, y el gobierno de la cosa pública ha de tener como ideal el pluralismo. Es decir, las tramas de la vida social deben hacer posible la existencia y el desarrollo de cualquier intento de expresión humana. El pluralismo, precisamente porque tiende a afirmar todas las libres experiencias particulares con toda su autenticidad, no se sustenta en el relativismo sino en la valorización del compromiso personal con la verdad.

\footnotetext{
${ }^{49}$ DG, p. 168.

${ }^{50}$ Cfr. DG, p. 176.

${ }^{51}$ DG, p. 179.

${ }^{52}$ Cfr. Giussani Luigi, El yo, el poder, las obras. Contribuciones a partir de una experiencia, Encuentro, Madrid, 2001, pp. 165-168.
} 
No se trata de dudar de sí mismo ni de rebajar la propia identidad para que haya diálogo y espíritu democrático. "Espíritu abierto" no significa "apartar lo que nos separa y mirar sólo lo que nos une", primero, porque eso equivale a diluir la auténtica pluralidad y, segundo, porque sólo hay diálogo real donde hay identidad vital y racionalmente exigente, al par que sensibilidad por las razones consistentes del otro, porque así, lo que el otro es y vive, me concierne.

\section{Resumen}

En este artículo se examina y proyecta, en primer lugar, la idea de "razón pública" de John Rawls en su potencialidad con respecto a la racionalidad de ciertos derechos humanos fundamentales, como la libertad de conciencia, de educación y de asociación, que un estado democrático constitucional, configurado desde la concepción política de la justicia como equidad, debe garantizar en el marco de un pluralismo razonable. En segundo lugar, desde algunos tópicos antropológicos desarrollados desde San Agustín y H. Arendt, se intenta mostrar la base ontológica del pluralismo cultural y político, para articularla con la teoría del liberalismo político y su concepción de la unidad política estatal. En tercer lugar, se analiza y revisa la tensión entre "lo racional" y "lo razonable" en Rawls, para mostrar el anclaje de una conceptuación dual de la azón pública, como "razón pública cultural" y "razón pública política". Finalmente, se plantea la dialéctica de la razón pública dual en función de una democracia viva en el marco teórico del liberalismo político.

Palabras claves. "Rawls", "razón pública", "pluralismo razonable".

\section{Abstract}

In this essay the idea of "public reason" of John Rawls in his potentiality is examined and projected, firstly, with regard to the rationality of certain fundamental human rights, as the freedom of conscience, the freedom of education and of association, which a democratic constitutional state shaped on the ground of the political conception of the justice as fairness, must guarantee in the framework of a reasonable pluralism. Secondly, I aim to show starting from some anthropological topics developed from St Augustin and H. Arendt, the ontological base of the cultural and political pluralism, to articulate it with the theory of the political liberalism and its conception of the political unit of the state. Thirdly, the tension between 'the rational thing' and 'the reasonable thing' in Rawls is analyzed and checked, to show the anchorage of a dual conceptuation, cultural and political of the public reason. Finally, I trace in the theoretical frame of the political liberalism the dialectics of the public dual reason in an alive democracy.

Key words: "Rawls", "public reason", "razonable pluralism". 